\title{
THE CARDIAC OUTPUT IN PATIENTS WITH CHRONIC ANEMIA AS MEASURED BY THE TECHNIQUE OF RIGHT ATRIAL CATHETERIZATION ${ }^{1}$
}

\author{
By E. S. BRANNON, A. J. MERRILL, J. V. WARREN, ANd E. A. STEAD, JR. \\ (From the Medical Service of Grady Hospital and the Department of Medicine, \\ Emory University School of Medicine, Atlanta)
}

(Received for publication August 24, 1944)

Many patients with circulatory failure either from hemorrhage or heart failure have anemia. In these patients, the cardiac output may be within normal limits and yet the circulation may be inadequate. The question immediately arises as to what is the effect of anemia on the requirements of the tissues of the body for blood. Before it can be determined whether a given patient with anemia has an adequate circulation, it is necessary to know how anemia per se affects the cardiovascular system and what level of cardiac output should be expected for a given hemoglobin concentration. Studies on the circulation were, therefore, carried out on patients with chronic anemia in whom the picture was not complicated by shock and by the marked decrease in total blood volume which are so often present in the acute anemia produced by hemorrhage.

\section{METHODS}

The cardiac output was measured by the utilization of the direct Fick principle. Samples of mixed venous blood from the right atrium and measurements of atrial pressure were obtained from an inlying atrial catheter, introduced into the venous system through the antecubital vein $(1,2)$. The oxygen consumption was determined by the analysis of a 2 -minute sample of expired air, using the method of Haldane. The metabolic rate was recorded as the percentage of deviation from the expected basal metabolism. The oxygen content of the blood was measured by the method of Van Slyke and Neill (3). A point $5 \mathrm{~cm}$. below the 4 th right costochondral junction was used as the reference point in reading the atrial pressure. The arterial pressure in the femoral artery was recorded optically by the method of Hamilton (4). The mean arterial pressure was measured by planimetric integration of the area beneath the tracing. The peripheral resistance was calculated by

1 The work described in this paper was done under a contract, recommended by the Committee on Medical Research, between the Office of Scientific Research and Development and Emory University School of Medicine. the formula (2):

$$
\mathrm{R}=\frac{\mathrm{Pm} \text { (mean pressure in } \mathrm{mm} . \mathrm{Hg}) \times 1332}{\text { C.O. (cardiac output in } \mathrm{ml} \text {. per sec.) }}
$$

The ventilation was calculated as liters of air ventilated per min. per sq. meter at $37^{\circ} \mathrm{C}$. and the prevailing barometric pressure (5). The hemoglobin concentration was measured with a photoelectric colorimeter. Heparin was used as the anti-coagulant to determine the hematocrit reading.

\section{RESULTS}

Twenty-four sets of observations were made on 18 anemic subjects (Table I). When the hemoglobin concentration was below 7 grams per 100 $\mathrm{ml}$. and the hematocrit reading was below 20 , the cardiac output in the resting basal state was usually increased. In the 9 experiments in which the hematocrit reading was below 14 and the hemoglobin below 5 grams, the average cardiac index was 6.5. In the 5 patients with hemoglobin concentration between 5 and 7 grams per $100 \mathrm{ml}$., the cardiac index averaged 4.7 ; in the 5 between 7 and 9 grams, it averaged 4; and in the 5 patients between 9 and 13 grams, it averaged 3.1.

At the bottom of Table I are given the average values for the various aspects of the circulation in patients with severe anemia (hemoglobin below 7 grams), in patients with moderate anemia (hemoglobie over 7 grams), and in a group of normal young male subjects. The cardiac output, the arteriovenous oxygen difference, and the atrial pressure readings were not significantly altered by moderate chronic anemia. The values for oxygen consumption, metabolic rate, ventilation, femoral arterial pressure, and pulse rate tended to be slightly higher in the moderately anemic than in the normal control group. This is probably not the result of moderate anemia, but of different criteria used in selecting the persons composing the two groups. The moderately anemic subjects 
were a heterogeneous group of patients of varying ages in whom minor degrees of vascular disease may have been present and in whom it was impossible to eliminate a certain amount of apprehension connected with the experiment. For these reasons, the moderately anemic group is a better control series to determine the effects of anemia on certain aspects of the circulation than is the group of carefully selected normal males. In the severely anemic patients, the diastolic and mean arterial pressures and the peripheral resistance were lower than in the moderately anemic subjects. There was no significant difference in the atrial pressure readings in the two groups.

To be certain that the differences observed between the patients with moderate and severe anemia were actually caused by anemia and were not the result of anxiety or of chance selection of patients who normally had a hyperactive circulation, observations were made on 4 very anemic subjects before and after the hemoglobin level had been doubled by transfusions or by the administration of liver extract. The pulse rate always fell, the systolic and diastolic arterial pressures rose, the atrial pressure either remained unchanged or increased, and there was a dramatic increase in peripheral resistance. The arteriovenous oxygen difference always increased and the cardiac output decreased. These studies confirm the trends observed in comparing the circulation of normal subjects with the circulation of anemic patients.

\section{DISCUSSION}

When the hemoglobin concentration falls below 7 grams per $100 \mathrm{ml}$., requirements of the body for blood are increased (Figure 1). At low levels of hemoglobin, one observes that circulatory insufficiency develops while the cardiac output is still markedly above that found in normal subjects under similar conditions. For this reason, the finding of a normal cardiac output does not necessarily mean that a given patient is not in shock. The output must be evaluated in terms of the requirements of the body for blood. An analogous situation is found in certain patients with congestive heart failure and anemia. Congestive failure may occur while the heart is pumping more than the usual amount of blood. A cardiac output which is sufficient for a normal resting subject is insufficient for the anemic subject at rest and signs of congestive failure develop.

The heart rate tended to be elevated in anemia, but there was no obvious relationship between the pulse rate and the cardiac output in the series as a whole. In the 4 patients who were studied before and after increasing the hemoglobin level, both a fall in heart rate and cardiac output occurred.

There was no correlation between the atrial pressure and the cardiac output in these patients. In spite of the marked increase in cardiac output, there was no significant rise in atrial pressure. In 2 of the subjects who were studied before and after therapy for the anemia, the atrial pressure tended to rise as the volume of red cells increased and the cardiac output decreased. These data are in accord with our observations on moderate blood loss in which it was demonstrated that, within a certain range, the atrial pressure could be varied without changing the cardiac output (6). It was also found that anxiety caused a marked increase in cardiac output without an accompanying rise in atrial pressure (7).

The data reported here are in accord with other observations recorded in the literature. In a study of the effects of bleeding on the cardiac output in dogs, two workers (8) noted that individual dogs reacted to comparable degrees of anemia with considerable difference in the degree of increase in cardiac output. They state that in many animals a hemoglobin level of 60 to 70 per cent did not cause a rise in output, but that in others, with much milder anemia, the cardiac output was increased. They suggest that the more rapidly a given degree of anemia is produced the more is the output of the heart increased.

There has been no uniform agreement as to the level to which the hemoglobin concentration falls before the cardiac output is definitely increased. One author (9) noted no increase in cardiac output until the hemoglobin fell to around 30 per cent. Another (10) found a hyperactive circulation when the hemoglobin was below 50 per cent. Still others (11) believed that a considerably less degree of anemia caused a measurable rise in cardiac output. In our patients, there was consistent increase in cardiac output when the 
E. S. BRANNON, A. J. MERRILL, J. V. WARREN, AND E. A. STEAD, JR.

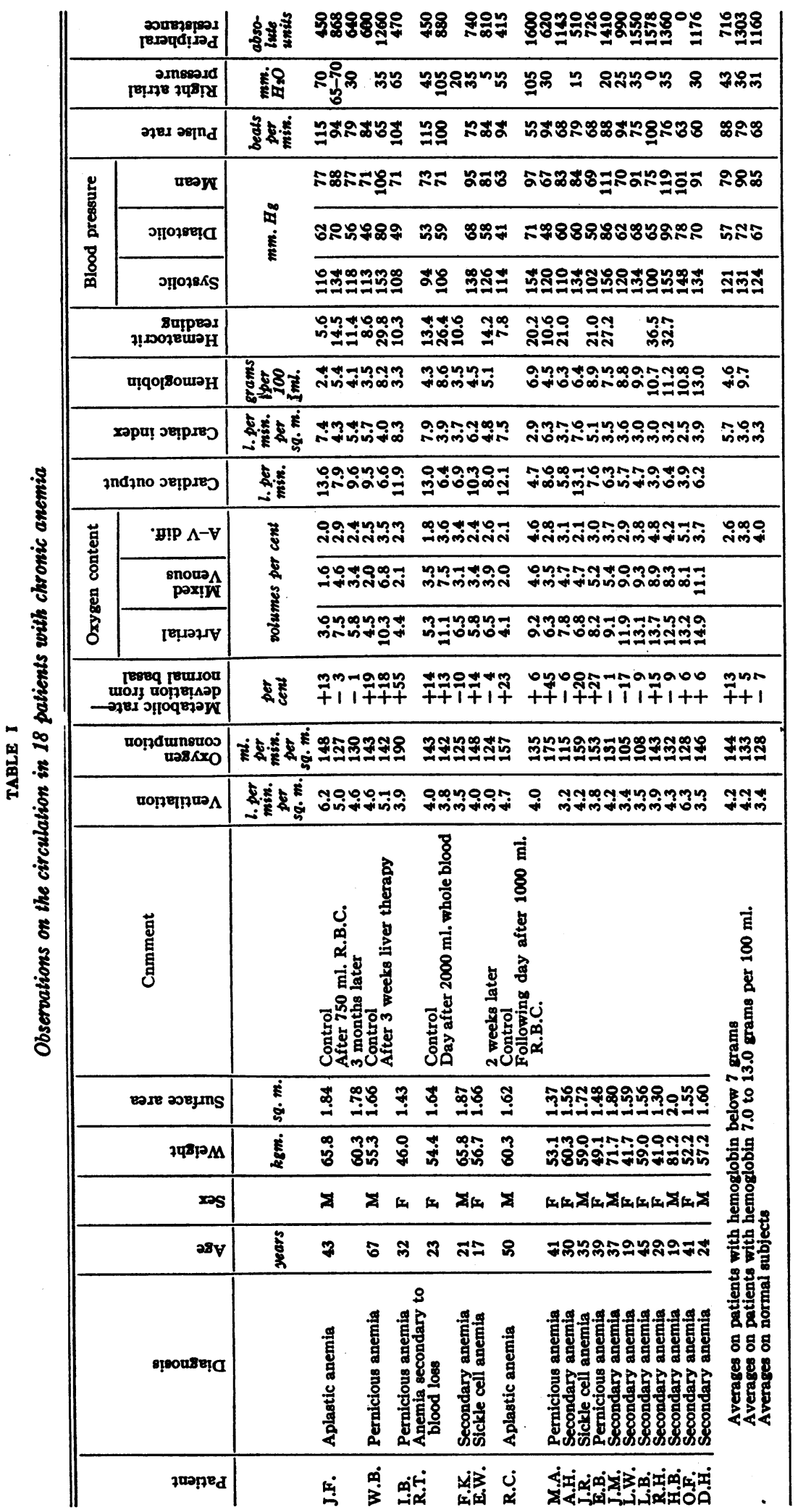




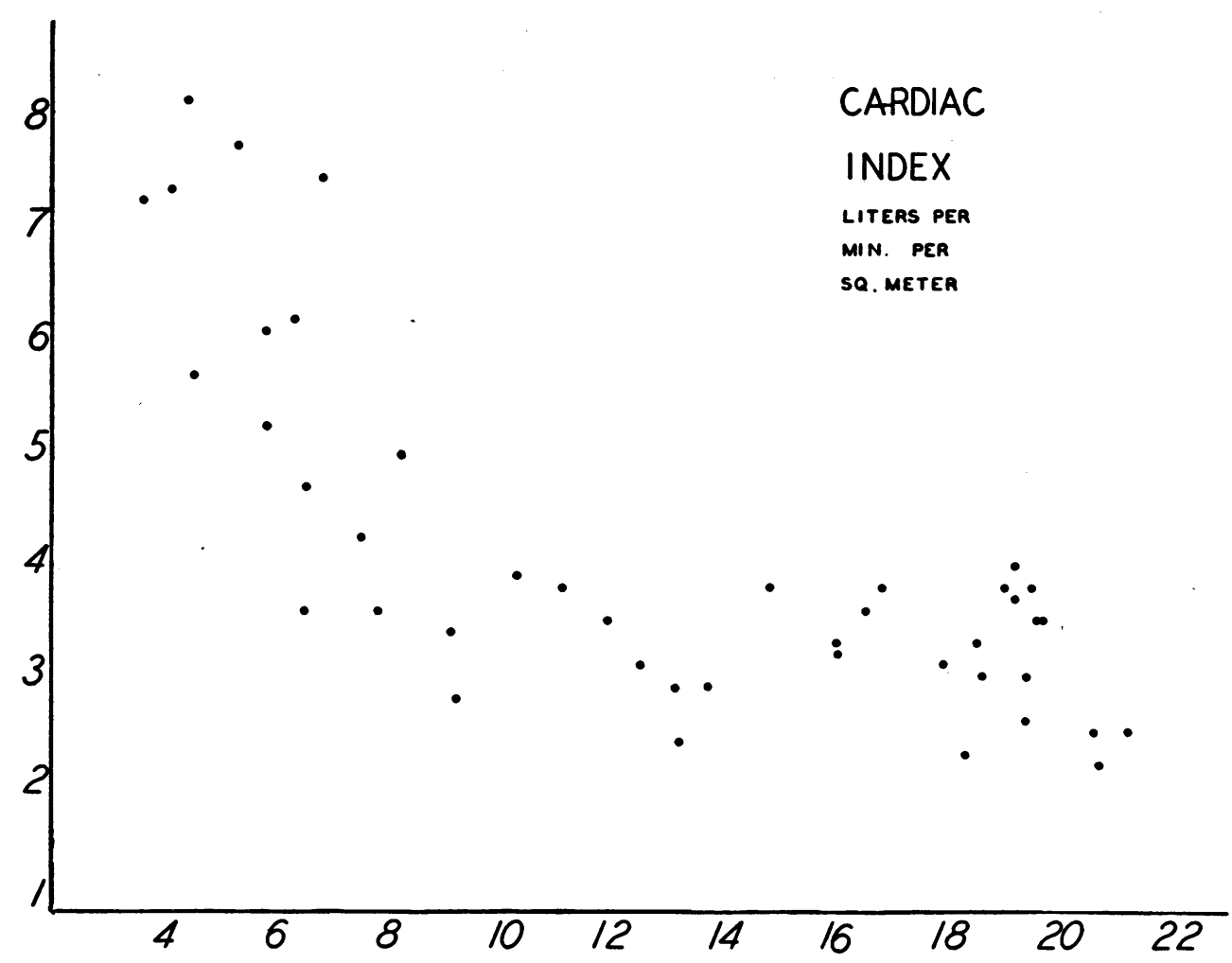

\section{ARTERIAL OXYGEN CONTENT VOLUMES PER CENT}

Fig. 1. Relationship Between the Cardiac Index and the Oxygen Content of the Arterial Blood

hemoglobin concentration was less than 7 grams per cent. This corresponds to a hemoglobin of around 50 per cent.

\section{SUMMARY}

1. Twenty-four sets of data were obtained on 18 anemic subjects. Atrial pressure readings and samples of mixed venous blood for determination of the cardiac output were obtained through a catheter introduced into the right atrium. The femoral arterial pressure was recorded optically by the method of Hamilton.

2. No consistent change in the circulation was observed when the hemoglobin level was above 7 grams per $100 \mathrm{ml}$. Below that level, the cardiac output at rest was increased, the arteriovenous oxygen difference and the peripheral resistance were decreased. The atrial pressure was not changed.
3. In 4 patients, observations were made before and after the hemoglobin had been doubled by transfusion or by the administration of liver extract. In each patient, the pulse rate fell, the diastolic and mean arterial pressures and peripheral resistance rose, and the cardiac output decreased.

4. When the hemoglobin level falls below 7 grams per $100 \mathrm{ml}$., the requirements of the body for blood are increased. This explains why anemic subjects may have circulatory insufficiency manifested by either shock or heart failure, while the heart is pumping as much or more blood as would be required by a normal subject under similar conditions.

This work was done with the technical assistance of Miss Maurine Giese, Miss Eloise Cavin, Mrs. Janet Stegeman, and Mrs. Jane Bailey. 


\section{BIBLIOGRAPHY}

1. Cournand, A., and Ranges, H. A., Catheterization of the right auricle in man. Proc. Soc. Exper. Biol. and Med., 1941, 46, 462.

2. Goldring, W., and Chasis, H., Hypertension and Hypertensive Disease. Appendix B. The Commonwealth Fund, New York, 1944.

3. Van Slyke, D. D., and Neill, J. M., The determination of gases in blood and other solutions by vacuum extraction and manometric measurement. J. Biol. Chem., 1924, 61, 523.

4. Hamilton, W. F., Brewer, G., and Brotman, I., Pressure pulse contours in the intact animal. I. Analytical description of a new high-frequency hypodermic manometer. Am. J. Physiol., 1934, $107,427$.

5. Cournand, A., and Richards, D. W., Jr., Pulmonary insufficiency. I. Discussion of physiological classification and presentation of clinical tests. Am. Rev. Tuberc., 1941, 44, 26.

6. Warren, J. V., Brannon, E. S., Stead, E. A., Jr., and Merrill, A. J., The effect of venesection and the pooling of blood in the extremities on the atrial pressure and cardiac output in normal subjects with observations on acute circulatory collapse in three instances. J. Clin. Invest., 1945, 24, 337.

7. Stead, E. A., Jr., Warren, J. V., Merrill, A. J., and Brannon, E. S., The cardiac output in male subjects as measured by the technique of right atrial catheterization. Normal values with observations on the effect of anxiety and tilting. J. Clin. Invest., 1945, 24, 326.

8. Blalock, A., and Harrison, T. R., The regulation of circulation. V. The effect of anemia and hemorrhage on the cardiac output of dogs. Am. J. Physiol., 1927, 80, 157.

9. Lundsgaard, C., Studies of oxygen in venous blood. J. Exper. Med., 1919, 30, 147.

10. Dautrebande, L., Blood output by heart in anemia. Compt. rend. Soc. de biol., 1925, 93, 1029.

11. Liljestrand, G., and Stenstrom, N., Work of heart during rest; influence of variations in hemoglobin content of blood flow. Acta. med. Skandinav., $1925,63,130$. 